\section{E.COLI INFECTION AND NITRATE POISONING FROM DRINKING WATER IN INFANTS FROM CONSTANTA COUNTY}

C.M. Mihai ${ }^{1}$, M.R. Stoicescuㄹㄹ A. Balasa ${ }^{1}$, L. Mihai ${ }^{1}$

${ }^{1}$ Pediatric, Faculty of Medicine of Constanta, ${ }^{2}$ Microbiology, Immunology, Faculty of Pharmacy of Constanta, Constanta, Romania

Background: Sandy soils from Constanta seaside rural areas have an increased leaching potential under high rainfall. The use of nitrogen fertilizers and animal wastes for legume crops continue to supply the nitrogen, exposing infants younger than 6 months of age to nitrate poisoning and and $\mathrm{E}$ coli infection.

Objectives: To assess the nitrate poisoning resulting in methemoglobinemia in infants under 6 months of age from rural areas and the diarrheal disease associated with methemoglobinemia and fecal water contamination.

Methods: We retrospectively studied the files from 117 infants diagnosed with nitrate poisoning, between 2004 and 2009.

Results: Children involved in this study were coming from rural area of Constanta County . Methemoglobin levels in these infants ranged from $15 \%$ to $81 \%$, and were positively correlated with blood nitrate concentrations. $79 \%$ of the infants were described as having symptoms consistent with clinically significant methemoglobinemia, such as cyanosis and tachycardia and one developed hemolysis. In 34 cases, an E coli diarrhea was confirmed, due to contaminated well water use.

Not properly sited and poorly maintained septic systems were the cause of nitrate poisoning in more than $40 \%$ of our cases.

Water samples collected from the wells during the infants' illnesses contained nitrate-nitrogen concentrations between 35.8 and $71.2 \mathrm{mg} / \mathrm{L}$.

In 34 wells E.coli was identified as the causative agent of diarrheal disease.

Conclusions: The occurrence of cases of nitrate poisoning and E.coli diarrhea in infants, suggests that contaminated groundwater continues to be an important infant health problem in our county.

\section{ROLE OF POVERTY IN ISOLATED RURAL COMMUNITIES AS A RISK FACTOR FOR PARASITIC INFECTION IN SCHOOLCHILDREN FROM CONSTANTA COUNTY, ROMANIA}

\author{
C.M. Mihai ${ }^{1}$, M.R. Stoicescu ${ }^{2}$, A. Balasa ${ }^{3}$, L. Mihai ${ }^{1}$ \\ ${ }^{1}$ Pediatric, Faculty of Medicine of Constanta, \\ ${ }^{2}$ Microbiology and Immunology, Faculty of \\ Pharmacy of Constanta, ${ }^{3}$ Faculty of Medicine of \\ Constanta, Constanta, Romania
}

Background: Intestinal parasitic infections are a public health problem in Romania.

Objective: To detect socio-economic factors associated with intestinal parasite infection in rural school children.

Methods: This cross-sectional study was conducted in 3 rural communities with little access to medical examination. 158 children were examined. Mean age was 9.1 years. 474 stool samples were collected. All stool samples were examined with native lugol, formol-ether, Kinyoun acid-fast, methods. The tape test was used in every child. Socio-economic information was obtained using a questionnaire.

Results: Intestinal parasites identified were: Giardia (13.2\%), Ascaris lumbricoides (11.1\%), Enterobius vermicularis $(8.7 \%)$, Blastocystis hominis $(4.9 \%)$. $39 \%$ of the school children showed polyparasitism. Lack of sanitation, lower income, and defecation in open areas, unemployment, were the significant factors related to these infections ( $P<0.05$ for each). In $95 \%$ of cases the construction of the latrines was undertaken by the community members themselves, using locally available material and local labor. Children from: less educated families $(P=0.000)$, low socio-economic status of the family $(P<0.05)$, family size and number of rooms in houses $(P=$ 0.000 ) showed higher risk of intestinal parasitism. There was a significant difference between infection rate and source of water for human consumption $(P$ $=0.05$ ). Unproperly built toilets and lack of washing facilities in schools, including lack of soap were linked to a high prevalence of parasitic infections in this study-group.

Conclusion: Efforts should be made to educate people from isolated rural areas regarding the danger of poor sanitation. 